\title{
Philophthalmus Lucipetus (Trematoda, Philophthalmidae) Cercariae in Molluscs Melanoides Kainarensis
}

\section{IJCRR}

Section: Life

Sciences

Sci. Journal Impact

Factor: $6.1(2018)$

ICV: 90.90 (2018)

Scopus'

\section{Ulugbek Abdulakimovich Shakarbaev ${ }^{1}$, Firuza Djalaliddinovna Akramova ${ }^{1}$ Djalaliddin Azimovich Azimov ${ }^{1}$}

Institute of Zoology, Academy of Sciences of the Republic of Uzbekistan, Tashkent, Uzbekistan.

\section{ABSTRACT}

Cercariae of Philophthalmus lucipetus (Rudolphi, 1819) were detected in molluscs Melanoides kainarensis Starobogatov et Izzatullaev, 1980. Of the 4,629 examined individuals of M. kainarensis from Boshkhovuz, a warm body of water in the Karnabchul steppe (Nurabad District, Samarkand Province), 407 individuals $(9.01 \%)$ were infected with cercariae and parthenitae of flukes from the genus Philophthalmus Looss, 1899, whose species was identified as Ph. lucipetus.

Key Words: Melanoides kainarensis, Philophthalmus lucipetus, Parthenitae, Cercariae, Molluscs.

\section{INTRODUCTION}

The geographical range of Philophthalmus lucipetus ${ }^{1}$ is quite wide. Populations of this trematode were recorded in many countries in Europe, Asia, Africa, and Americas in various ecological groups of birds. Mature trematodes parastitise the conjunctival sac and cause a grave disease in agricultural and game birds. In CIS countries this trematode species was recorded in Anser anser in Ukraine ${ }^{2}$. Populations of Ph. lucipetus were also recorded in many other countries in geese, ducks, chickens, peacocks, turkeys, ostriches and rheas ${ }^{3-10}$. Molluscs Melanoides tuberculatus, Fagotia acicularis, Amphimelania holandri, Melanopsis praemorsa, Pleurocerca acuta and Tarebia granifera were identified as intermediate hosts of this trematode ${ }^{11-14}$.

Mature forms of $\mathrm{Ph}$. lucipetus has not yet been recorded in the wild birds of Uzbekistan. However, the recent record of cercariae in M. Kainarensis and identification of this species as a new intermediate host of this trematode in Uzbekistan, as well as the registration of an outbreak of the infection within a limited area, strongly demanded some comprehensive research.

The goal of this work was to establish the rate of infection with $\mathrm{Ph}$. lucipetus cercariae in populations of $\mathrm{M}$. kainarensis in Uzbekistan and reconstruct the life cycle of this trematode in an experiment.

\section{MATERIALS AND METHODS}

This work was based on the results of faunistic and experimental research carried out in 2010-2019 to study the fauna and morphology and biology of cercariae developing in freshwater mollusks. The mollusks were collected from a warm spring (Boshkhovuz in the Karnabchul steppe, Nurabad District, Samarkand province) following a commonly accepted method ${ }^{15}$. The stationary survey was carried out between June and August in 2010-2018 and in January 2019. The total number of examined mollusk individuals from the spring was 4,629 (fig. 1). The species were identified using the following works ${ }^{16-17}$. The collected molluscs were delivered to a laboratory, where each individual was placed in a separate glass with $50 \mathrm{ml}$ of tap water at a temperature of $20-25{ }^{\circ} \mathrm{C}$. Emerging cercariae were surveyed with a naked eye or using a МБС-10 binocular microscope.

The morphology of the cercariae that left the mollusks' bodies and stayed in the water was studied using vital staining $-0.05 \%$ neutral red and $0.05 \%$ Nile blue ${ }^{18-20}$. Carmine acetic was used in whole mount staining. The digestive gland, heart, and aorta were extracted from naturally infected mollusks M. kainarensis to study parthenogenetic forms. The collected mother and daughter rediae were examined through a microscope. The trematode larvae were photographed and sketched. Statistical data were processed using software Biostat 2007 and Microsoft Office Excel 2003.

\section{Corresponding Author:}

Ulugbek Abdulakimovich Shakarbaev, Institute of Zoology, Academy of Sciences of the Republic of Uzbekistan, Tashkent, Uzbekistan. Email: ushakarbaev@mail.ru

ISSN: 2231-2196 (Print) ISSN: $0975-5241$ (Online)

Received: 25.04 .2020

Revised: 10.06 .2020

Accepted: 16.06 .2020

Published: 22.07 .2020 


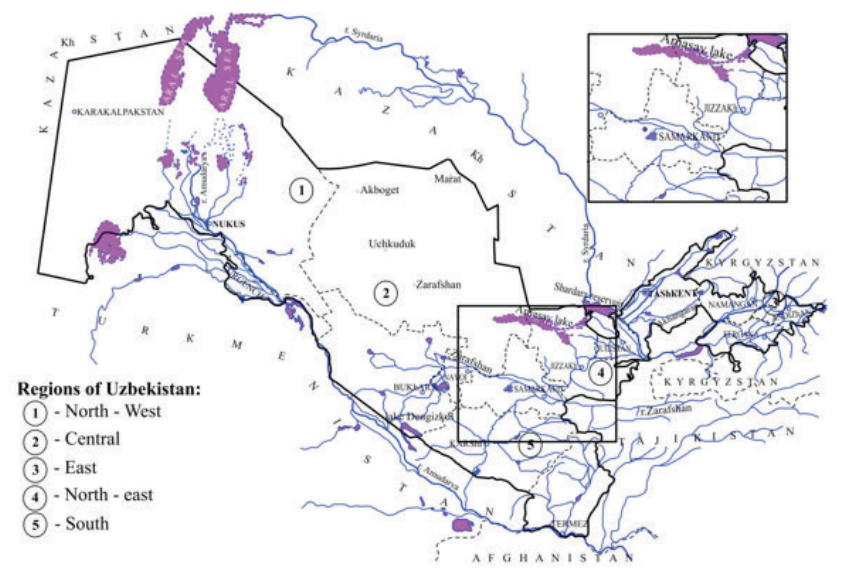

Figure 1: Location of the site where the material was collected

\section{RESULTS}

Populations of M. Kainarensis live in warm springs and streams and ponds resulting from these springs at a depth of $15-20 \mathrm{~cm}$ on stony or limy bottoms and show a density of 130-160 individuals per $1 \mathrm{~m}^{2}$ (fig. 1).
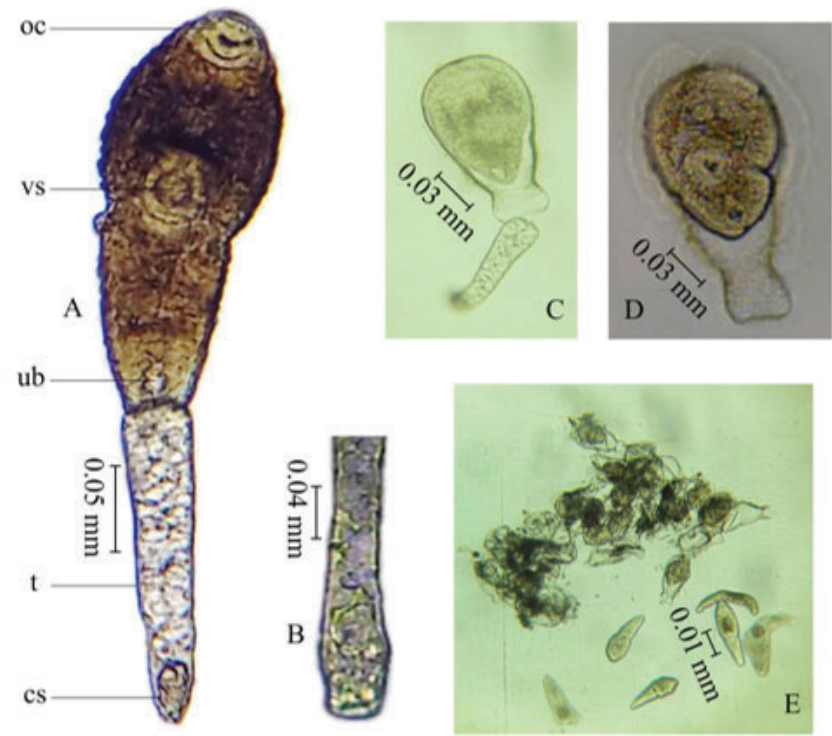

Figure 2: Philophthalmus lucipetus (Rudolphi, 1819): A - cercaria: os - oral sucker; vs - ventral sucker; ub- urinary bladder; t- tail; cs- caudal sucker; B- cercaria's tail tip; C- casting of the tail; D-adolescaria.

Outside Uzbekistan M. kainarensis was recorded in Turkmenistan and Afghanistan. The lifespan is 5-8 years. The diet consists of bacteria and microalgae ${ }^{21,22}$.

Of 4,629 individuals of M. kainarensis studied in June, July, and August 2017-2018 and January 2019, 407 (9.01\%) were infected with trematode $\mathrm{Ph}$. lucipetus cercariae (Table 1, fig.
2). Mother rediae and first daughter rediae were localized in the mollusk's heart and the beginning of the aorta. Developed daughter rediae with formed cercariae were found in the digestive gland. This was supported by numerous publications related to $\mathrm{Ph}$. lucipetus and other species from the genus Philophthalmus. We shall discuss only the results related to cercariae of the species under study.

\begin{tabular}{|c|c|c|c|}
\hline \multicolumn{2}{|c|}{ Time of the year } & \multirow{2}{*}{$\begin{array}{c}\text { No. of examined } \\
\text { individuals } \\
410\end{array}$} & \multirow{2}{*}{$\begin{array}{c}\text { Rate of infection } \\
\qquad \%) \\
21(5.2)\end{array}$} \\
\hline 2017 & June & & \\
\hline & July & 597 & $63(10.5)$ \\
\hline & August & 748 & $82(11.0)$ \\
\hline \multirow[t]{3}{*}{2018} & June & 1,104 & $63(5.7)$ \\
\hline & July & 781 & $71(9.1)$ \\
\hline & August & 896 & $100(11.2)$ \\
\hline 2019 & January & 93 & 7 (10.4) \\
\hline Total & & 4,629 & 407 (9.01) \\
\hline
\end{tabular}

The prevalence shown by mollusks in the wild of Uzbekistan varied depending on the season and ranged between $5.2 \%$ and $11.2 \%$.

Given below are the basic morphometric parameters of $\mathrm{Ph}$. Lucipetus cercariae extracted from mollusk M. kainarensis and encysted adolescariae in the external environment.

Cercaria. The studied cercariae (20 individuals) had relatively large dimensions and in most cases showed a body length equal to the length of the tail. The body is oval and elongated, $0.53-0.65 \mathrm{~mm}$ long and $0.11-0.14 \mathrm{~mm}$ wide. The maximum width is recorded just in front of the ventral sucker. The tail is $0.46-0.52 \mathrm{~mm}$ long and $0.03-0.06 \mathrm{~mm}$ wide. The tip of the tail looks cut and has a sucker-like projection provided with glandular cells with ducts open at the tail tip. The subterminal oral sucker has a rounded shape and is 0.04-0.06 mm long and 0.04-0.05 $\mathrm{mm}$ wide. The ventral sucker is $0.06-0.07 \mathrm{~mm}$ long and $0.08 \mathrm{~mm}$ wide. The oral fissure is subterminal.

The prepharynx is well-developed, the pharynx is oval and is $0.03-0.04 \mathrm{~mm}$ long and $0.01-0.02 \mathrm{~mm}$ wide; the oesophagus is relatively long $-0.10-0.12 \mathrm{~mm}$ - and bifurcates in front of the ventral sucker; the intestinal branches are long, reach the rear tip of the body and have blind ends. The glandular cells are numerous and have ducts opening in the front part of the body. The excretory system is typical of all flatworms and consists of a large number of flame cells, a system of ducts, and a urinary bladder. The excretory system is expressed by formula $2[(3+3+3)+(2+2+2)]=30$. Sexual rudiments are 
formed by cellular masses lying lengthwise in the space between the bifurcation of the aesophagus and the front part of the urinary bladder (fig. 2).

The evolution of cercariae into adolescariae takes relatively little time. At $20-25^{\circ} \mathrm{C}$ cercariae that have just left the body of a mollusk, their intermediate host, get encysted in 1.5-2 minutes. In 1-3 hours this process extends to 2.5-3 minutes (based on the observation of 40 cercariae, 20 individuals from each age group of larvae). The encystation is usually preceded by the attachment of the cercaria with its tail to a substrate and the tail's detachment from the body. This phenomenon is characteristic only of this group of trematodes. The adolescariae usually are pear-shaped, $0.48-0.52 \mathrm{~mm}$ long, and $0.20-0.24 \mathrm{~mm}$ wide.

Identical figures were shown by $\mathrm{Ph}$. Lucipetus cercariae extracted from other mollusk species, mainly M. tuberculatus 23-28. The larvae did not vary greatly in size depending on the mollusk host (Table 2).

Table 2: Comparative parameters of Philophthalmus lucipetus cercariae, $\mathbf{m m}$.

\begin{tabular}{|c|c|c|c|c|c|}
\hline \multirow[t]{3}{*}{ Body parts } & \multicolumn{5}{|c|}{ Intermediate host } \\
\hline & \multirow{2}{*}{$\begin{array}{c}\text { Pleurocerca acuta } \\
\text { (acc.to West, 1961; USA) } \\
\text { Limit }\end{array}$} & \multicolumn{2}{|c|}{$\begin{array}{l}\text { Melanoides tuberculatus } \\
\text { (Pinto and Melo 2010; Brazil) }\end{array}$} & \multicolumn{2}{|c|}{$\begin{array}{l}\text { Melanoides kainarensis } \\
\text { (our data; Uzbekistan) }\end{array}$} \\
\hline & & Limit & $\mathbf{M} \pm \mathbf{m}$ & Limit & $\mathbf{M} \pm \mathbf{m}$ \\
\hline Body: length & $0.54-0.67$ & $0.42-0.58$ & 0.53 & $0.53^{-0.65}$ & $0,59 \pm 0.014$ \\
\hline width & $0.12-0.13$ & $0.11-0.14$ & 0.12 & $0.11-0.14$ & $0.12 \pm 0.003$ \\
\hline Oral sucker: length & 0.06 & $0.05^{-0.06}$ & 0.05 & $0.04-0.06$ & $0.046 \pm 0.002$ \\
\hline width & $0.04-0.05$ & $0.04-0.06$ & 0.05 & $0.04-0.05$ & $0.041 \pm 0.001$ \\
\hline Ventral sucker: length & $0.06-0.07$ & $0.06-0.07$ & 0.06 & $0.06-0.07$ & $0.06 \pm 0.001$ \\
\hline width & - & 0.06-0.o8 & 0.07 & $0.07-0.08$ & $0.071 \pm 0.001$ \\
\hline Pharynx : length & $0.03-0.04$ & - & - & $0.03-0.04$ & $0.03 \pm 0.001$ \\
\hline width & $0.01-0.02$ & - & - & $0.01-0.02$ & $0.01 \pm 0.001$ \\
\hline Oesophagus: length & $0.10-0.11$ & - & - & $0.10-0.12$ & $0.10 \pm 0.002$ \\
\hline Head glands & 20 pairs & \multicolumn{2}{|c|}{ Numerous } & \multicolumn{2}{|c|}{20 pairs } \\
\hline Excretory system & $2[(3+3+3)+(2+2+2)]=30$ & - & - & \multicolumn{2}{|c|}{$2[(3+3+3)+(2+2+2)]=30$} \\
\hline Tail: length & $0.93^{-1.14}$ & $0.30-0.48$ & 0.43 & $0.46-0.52$ & $0.49 \pm 0.006$ \\
\hline width & $0.04-0.05$ & $0.03^{-0.06}$ & 0.05 & $0.03-0.06$ & $0.042 \pm 0.003$ \\
\hline
\end{tabular}

\section{DISCUSSION}

Various authors described about 36 species from the genus Philophthalmus ${ }^{6-9}$. The validity of the number of species arouses doubts, since they are described on the basis of a limited amount of material, without taking into account the parasites' changeability depending on a number of factors. The structure of the genus, species diversity, and biology are currently being studied and revised most actively ${ }^{1-5}$. The research ${ }^{29}$ showed identity between $\mathrm{Ph}$. gralli and $\mathrm{Ph}$. lucipetus. These authors presented $\mathrm{Ph}$. gralli as a synonym for $\mathrm{Ph}$. lucipetus, which quite corresponds with the priority principles. We agree with this viewpoint.

When studying mollusks M. kainarensis on 15 June 2013, we detected rediae and cercariae from the genus Philophthalmus, which were identified as the species $\mathrm{Ph}$. lucipetus. No birds infected in a natural way were recorded in Uzbekistan. The parthenogenetic forms and cercariae found in mollusks
M. kainarensis in an isolated body of water in Uzbekistan, probably, were brought by aquatic and semi-aquatic birds coming from other regions as part of their seasonal migration. The existence of certain biological pre-conditions led to the emergence of a new focus of infection in this territory. Mollusk M. kainarensis became a new intermediate host of this trematode.

As was already mentioned, a number of mollusc species, such as Pleurocerca acuta, Tarebia granifera, Fagotia acicularis, Amphimelatus holandri, Melanoides tuberculatus, Melanopsis praemorsa, and Melanoides kainarensis were identified as intermediate hosts of trematode Philophthalmus lucipetus, which ensures stability of the parthenitamollusc system and facilitates the spread of the infection. The next stage in the life cycle of the cercariae is its penetration into the external environment. Ph. lucipetus larvae usually emerge at twilight or night, while some of them come out in the morning hours. 
After floating for a while, cercariae usually attach themselves with the tip of their tail to the substrates of the water body. In our experiments, the larvae fixed themselves to the walls of the glasses or Petri dishes so tight that they stopped moving forward. When their tail tip is 'immobilised,' the cercariae place their body vertically and start making active pendular or circular movements to facilitate the detachment of the body from the tail. Soon after the body gets encysted and turns into an adolescaria. The adolescariae form several groups on the walls of the vessel (a glass or Petri dish), from 5 to 10 individuals in each group, gathering into separate microconglomerations.

A number of researchers noted the common morphological and biological characteristics of Philophthalmidae cercariae, which consist in the transformation of the tail due to its loss of the locomotor function into an anchoring organ ${ }^{11-15}$.

The thing is that in free-living cercariae the oral and ventral suckers act as anchoring organs and contain secreting glandular cells whose ducts go as far as the surface of the suckers. The tail stem performs the locomotor function ${ }^{10}$. This is a feature typical of cercariae of most trematodes. Unlike other trematode cercariae, the distal end of the tail in Philophthalmidae cercariae has a sucker-like organ provided with glandular cells secreting adhesive substance the cercariae use to stick to a substrate ${ }^{19-23}$.

The described morphological and biological characteristics shown by Philophthalmidae are quite functional. The abovementioned transformations, probably, allow cercariae concentrate as densely as possible on a limited area on the surface of a substrate, accelerate the encystation of the parasite in the external environment and enhance the opportunity to parasitize definitive hosts.

By their morphological and biological features, the cercariae are, without exaggeration, unique. These features most brightly show themselves in this very group and are obviously of great importance for the study of trematodes' phylogenesis.

\section{Acknowledgement: none}

\section{Conflict of interest: none}

Financial support: none

\section{REFERENCES}

1. Atayev, G. L. The influence of temperature on the development and biology of rediae and cercariae of Philophthalmus rhionica (Trematoda). Parasitology, 25 (4): pp.349-359, 1991.

2. Galaktionov, K. V., Dobrovolsky, A. A. The hermaphrodite generation of trematodes. Leningrad, Nauka, p.193, 1987.

3. Galaktionov, K. V., Dobrovolsky, A. A. The origin and evolution of trematodes' life cycles. Saint Petersburg, Nauka, p.403, 1998.
4. Ginetsinskaya, T. A. Trematodes, their life cycles, biology and evolution. Leningrad, Nauka, p.411, 1968.

5. Groshavt, Ya. Philophthalmidae. A guide to trematodes of the fish eating birds of the Palaearctic. Moscow, Nauka, pp.136$145,1985$.

6. Zhadin, V. I. Molluscs in the fresh and brackish waters of the USSR. Guides to the fauna of the USSR. Academy of Sciences of the USSR. Moscow, Leningrad, p.374, 1952.

7. Red Data Book of Uzbekistan. Animals. Tashkent, Chinor ENK, 2: pp.40-41, 2009.

8. Likharev, I. M., Starobogatov, Ya. I. Materials on the mollusc fauna of Afghanistan. From the collection Molluscs and Their Role in Biocoenoses and the Formation of Faunas. A treatise by the Institute of Zoology, Academy of Sciences of the USSR, Leningrad, Nauka, 42: pp.159-198, 1967.

9. Smogorzhevskaya, A. A. Helminths of the aquatic and semiaquatic birds of the fauna of Ukraine. Kiev, Naukova dumka, p.414, 1976.

10. Starobogatov, Ya. I., Izzatullayev, Z. I. Molluscs from the family Melanoididae (Gastropoda, Pectinibanchia) in Central Asia and adjacent territories. Zoological magazine, Nauka, LIX (1): pp.23-31, 1980.

11. Tikhomirov I. A. The life cycle of Philophthalmus rhionica sp. nov. (Trematoda: Philophthalmidae). The abstract of a thesis by $\mathrm{PhD}$ in Biology. Leningrad, p.20, 1980.

12. Chernogorenko M. I. Trematode larvae in the molluscs of the Dnepr and its reservoirs. Academy of Sciences of the Ukrainian SSR. Kiev, Naukova dumka, p.208, 1983.

13. Abdul-SalamJ., SreelathaB.S., AshkananiH. The eye fluke Philophthalmus hegeneri (Digenea: Philophthalmidae) in $\mathrm{Ku}-$ wait Bay. Kuwait J. Sci. Eng. 31(1): pp.119-133, 2004.

14. Alicata J.E. Life cycle and development stages of Philophthalmus gralli in intermediate and final hosts. J. Parasitol., 48: pp.47-54, 1962.

15. Ching H.L. The developmental variation of Philophthalmus gralli (Mathis and Leger, 1910) with a comparison of species of Philophthalmus (Looss, 1899). Proceedings of the Helminthological Society of Washington, 28: pp. 130-138, 1961.

16. Dailey M., Ellin R., Paras A. First report ofparasites from pinnipeds in the Galapagos Island, Ecuador, with a description of a new species of Philophthalmus (Digenea: Philophthalmidae). Journal of Parasitology, 91:pp.614-617, 2005.

17. Greve J.H., Harrison G.J.Conjunctivitis caused by eye flukes in captive-reared ostriches. Journal of the American Veterinary Association, 177: pp.909-910, 1980.

18. Howell M.J., Bearup A.J. The life histories of two bird trematodes of the family Philophthalmidae. Proceedings of the Linnaean Society of New South Wales, 92: pp.182-194, 1967.

19. Kanev I., Nollen P.M., Vassilev I., Radev V., Dimitrov V. Redescription of Philophthalmus lucipetus (Rudolphi, 1819)(Trematoda: Philophthalmidae) with a discussion of its identity and characteristics. Annalen des Naturhistorisches Museum Wien 94/95B, pp.11-34, 1993.

20. Literak I., Heneberg P., Sitko J., Wetzel E.J., Cardenas Callirgos J.M., Capek M., Valle Basto D., PapousekI. Eye trematode infection in small passerines in Peru caused by Philophthalmus lucipetus, an agentwith a zoonotic potential spread by an invasive freshwater snail.Parasitology International, 62: pp.390396, 2013.

21. Mathis C., Leger M. Douve oculaire de la poule. Bulleten Societe de Pathologie Exotique, 3: pp.245-251, 1910.

22. Mukaratirwa S., Hove T., Cindzi Z.M., Maononga D.B., Taruvinga M., Matenga E. First report of a field outbreak of the orien- 
tal eye-fluke, Philophthalmus gralli (Mathis \& Leger 1910), in commercially reared ostriches (Struthio camelus) in Zimbabwe. Onderstepoort J. Vet. Res., 72: pp.203-206, 2005.

23. Nollen P.M., Murray H.D. Philophthalmus gralli: identification, growth characteristics, and treatment of anOriental eyefluke of birds introduced into the continental United States.J. Parasitol., 64: pp.178-180, 1978.

24. Pinto H.A. Infecção natural de Melanoides tuberculata (Mollusca: Thiaridae) por Centrocestus formosanus (Trematoda: Heterophyidae) e por Philophthalmus gralli (Trematoda: Philophthalmidae) no Brasil. Universidade Federal de Minas Gerais Instituto de Ciencias Biologicas Belo Horizonte, pp.55-67, 2009.

25. Pinto H.U., de Melo A.L. Melanoides tuberculatas intermediate host of Philophthalmus gralli in Brazil. Revista do Instituto de Medecina Tropical de São Paulo, 52: pp.323-327, 2010.
26. Radev V., Kanev I., Gold D. Life cycle and identication of eye fuke from Israel transmitted by Melanoides tuberculata (Muller, 1774). Journal of Parasitology, 86: pp.773-776, 2000.

27. Radev V., Kanev I., Fried B. Comments on eye-flukes (Philophthalmidae Looss, 1819) in the genera Philophthalmus and Natterophthalmus, with a re-designation of the type-species of Natterophthalmus. Zootaxa, 1223: pp.19-22, 2006.

28. Rees F.G.Locomotion of the cercaria of Parorchis acanthus, Nicoll, and the ultrastructure of the tail. Parasitology,62(3): pp.489-503, 1971.

29. West A.F. Studies on the biology of Philophthalmus gralli Mathis and Leger, 1910 (Trematoda: Digenea). American Midland Naturalist, 66: pp.363-383, 1961. 